\title{
Flame Retardants Nanocomposites-Synergistic Effect of Combination Conventional Retardants with Nanofillers of the Flammability of Thermoset Resins
}

\author{
Ewa Kicko-Walczak ${ }^{1}$ and Grażyna Rymarz ${ }^{2}$ \\ 1. Institute for Engineering of Polymer Materials and Dyes, Piastów 05-820, Poland \\ 2. Branch of Paints and Plastics, Institute for Engineering of Polymer Materials and Dyes, Gliwice 44-100, Poland
}

\begin{abstract}
The consumption of thermoset resins as building polymers is approximately over one million tone word wide. The thermoset resins are proven construction materials for the technical and highly demanding applications of the transportation, electrical and building part industry. Heat stability, high thermal, low shrinkage, excellent mechanical properties are typical for their type of polymers. Above applications in addition to the mechanical properties also require good flame retardants of the materials. Undertaken activities refer to official draft, laws and legal recommendations in UE states. This paper presents positive effect of reduced flammability of thermoset resins (unsaturated polyester and epoxy resins) thanks to the use of nanocomposites containing multi-ingredient halogen-free flame retardants which combine conventional phosphorus/nitrogen modifiers interacting with nanofillers (oMMT (organomodified montmorillonite), EG (expandable graphite), graphene, GO (graphene oxide), nSi (nanosilica)).
\end{abstract}

Key words: FR (fire retardants), halogen-free FR additives, nanofillers, nanocomposites, flammability of thermoset resins, test methods.

\section{Introduction}

Reducing flammability of thermoset materials by addition of halogen compounds or inclusion in the structure of these polymers of a chemically bound halogen has been discontinued on a successive basis for ecological reasons. These compounds, even though they are very effective in decreasing flammability of thermoset materials and show favorable synergy effect, mainly in the halogen-antimony system, are characterized by emission of toxic products in combustion, mainly hydrogen chloride and hydrogen bromide. Their strong corrosive and irritant action, resulting from the use of aromatic bromine compounds, is a reason for limiting the use of this method and searching for alternative solutions. Undertaken activities refer to official drafts, laws and legal

Corresponding author: Ewa Kicko-Walezak, Ph.D., professor, research field: technology and modification of polymeric materials, particularly thermoset resins. E-mail: e.kicko-walczak@impib.pl. recommendations. In the territory of the EU (European Union), the REACH Regulation (with supplementary appendices) of the European Parliament and the Council has been in force since 2007, as the regulation for managing chemical policy in EU states [1]. The main objective of REACH is to control introduction of and transactions in already marketed chemical compounds in terms of safety of human health and life and natural environment. One of the major elements of legislative regulations (EU REACH regulation) is to assess especially controversial substances and to gradually withdraw them from the EU markets. In addition to REACH, EU states are also bound by the RoHS (Restriction of Hazardous Substances) Directive, which includes a ban on using halogen derivatives in the production of electronic and electric equipment. Most conventional flame retardants like halogenated organics have been limited in their utility due to health peoples and environmental concerns and other fire retardants like ATH (aluminum hydrates) are 
expensive and needed to be used in large quantities which the thermoset polymers lose its original mechanical properties. The application of ATH or magnesium hydroxide requires a very high loading of the filler within the polymer matrix. Loading levels of more than $60 \mathrm{wt} . \%$ are necessary to achieve a suitable flame retardancy. The disadvantages of these loading levels are high density and lack of flexibility of the final products, as well as low strength properties and problem in extrusion/compounding technical process.

These legislative initiatives are part of justified attempts and a necessity of searching for new, equally effective methods of reducing flammability of thermoset materials. Currently, reducing flammability of these polymers focuses on the use of halogen-free inorganic compounds, which, as additive modifiers, do not form chemical bonds with a polymer. From an industrial practice perspective, it is important that the desired flammability level should be achieved at the lowest possible concentration of a FR (flame retardant) [2]. Therefore, the current tendency among academic institutions is to focus on the use of multi-ingredient halogen-free FR systems, taking advantage of the synergy effect of their action [3, 4]. Synergy effects should be considered one of the most important phenomena related to the issues involving retardation of polymer flammability.

Recently, interest has arisen as to the use of additions in the form of nanocompounds as modifiers of multiple properties of polymers, including their thermal stability and fire resistance. Large interfacial surface and nanometric dimensions of modifier particles differentiate nanocomposites from traditional composites in a significant way. Nanocomposites avoid the disadvantages of these conventional flame retardants systems. Therefore, the assumption that nanomaterials formed this way make it possible to achieve significant progress and benefits for human kind and natural environment due to their distinctive properties compared to the properties demonstrated by macrometric size particles, has also rolled out to the issue of effective reduction in flammability of nanocomposite materials [5-7].

To produce polymer nanocomposites, including thermoset ones, natural layered aluminum silicates are usually used, such as smectites, kaolinites, halloysite nanotubes, including mainly MMT (montmorillonite), or modified compounds - by ionic exchange of MMT-based clay with quaternary ammonium salts. Layered silicates dispersed in a polymer matrix are the most popular form of hybrid nanocomposites. Commonly used MMT-modifying ammonium salts, which contain long alkyl carbon chains in their structure, make aluminum silicates acquire organophilic properties, improve their affinity to a polymer matrix and thus reinforce composites thermal stability which is determined by the length, number and saturation degree of alkyl chains. Nanocomposites modified this way by MMT demonstrate better thermal resistance, lower flammability and advantageous strength properties. This concerns, however, that mainly nanocomposites obtained with the use of polyolefines, polyamide, polystyrene [8-10], PVC [11] and other thermoplastics and elastomers, such as rubbers-SBR, BR, HNBR [12-15].

The results of experiments conducted in recent years on thermoset materials with modifications by mere MMT or organophilic MMT (oMMT) have confirmed a positive impact of this modification on strength properties, including mainly a significant increase in Young modulus of the products, but at the same time, it has turned out that their flammability reducing effect is less favorable [16-19].

The analysis confirms these observations and suggests a reason for this phenomenon. An effective multi-ingredient system has been proposed, which combines the joint effect of conventional flame retardants and selected nanocompounds, including expandable graphite, synthetic precipitated nanosilica [20]. The silica used in the experiments is a synthetic silicon oxide obtained by acidifying sodium silicate 

Nanofillers of the Flammability of Thermoset Resins

with sulfuric acid. In order to improve compatibility of silica and polymer matrix, acidification process was modified to obtain a suspension of precipitated silica, and then this suspension sustained separation and drying processes. The resultant silica in the form of spheroid pearls was pulverized or subjected to wet granulation. It should be noted that precipitated silica contains a number of silanol groups, which do have a positive impact on interaction with a polymer, but they also lead to reinforcement of hydrophilic properties. Therefore, in the course of analysis, modification of silica with pro-adhesive compounds was suggested, such as silane, borate titaniate compounds. Control of these parameters, combined with the control of $\mathrm{pH}$, temperature, reaction duration, molar ratio of reagents, makes it possible to obtain a portfolio of products from the group of nanosilica modifiers. In this analysis, nano-silica of the optimum set of properties was used, said properties being a sign of a possibility to obtain nanocomposites characterized by favorable thermal stability and lower flammability.

In order to reinforce flame retardation effect by the use of mere nanocompouns, polyphosphoric polymers were mainly used, IFR (intumescent flame retardants) in the form of melamine polyphosphate, ammonium polyphosphate and melamine borate showing a proven effectiveness in inhibiting the flame. In this process, benefits of phosphoric-nitrogen flame retardants were realized, showing a synergy effect in reducing HRR (heat release rate) and positive effects in reduction of flammability of structural compounds while using boron compounds [21, 22].

An important part of the work, consistent with the authors' intent, refers to taking advantage of the benefits of using hybrid flame retardants, combining phosphorous-derived modifiers of thermoset materials combustion process with selected modifiers when compared to the effect of reducing flammability level by using a single ingredient of the system only [23, 24]. In the course of experiments, optimum recipes and technological parameters for obtaining composite thermoset resins (unsaturated polyester resins and epoxy resins) with the use of multi-ingredient flame retardants. It was suggested which mechanism to use and how a deliberately chosen selection of multi-ingredient FR modifiers can have a positive impact on flame inhibition and lower smoke emissions.

\section{Experiments}

\subsection{Materials and Raw Materials}

- Polimal 103A-structural ortophthalic unsaturated polyester resin, produced by Zakłady Chemiczne "Organika-Sarzyna" S.A. viscosity in the range of $300-500 \mathrm{mPa} . \mathrm{s}$, styrene content of $35 \%$ or equivalent isophtalic polyester resin, DION Series produced by Reichhold, Inc. Company. Hardening system: two parts by weight of methyl-keton hydrogen peroxide Luperox K-1 and 0.4 parts by weight of cobalt naphthenate $(1 \% \mathrm{Co})$;

- Epidian 5 or 6-structural dianol-epochlorohydrine epoxy resins produced by Zakłady Chemiczne "Organika-Sarzyna" S.A. low-particle liquid resins of an epoxy number of 0.48-0.54 mol/100g. Hardening system: amine system. Hardening agent Z-1 in the amount of 12 parts by weight of Z-1 per 100 parts by weight of resin;

- MPP (melamine polyphosphate) - crystalline form of $\mathrm{P}_{2} 0_{5}$ content $=32-33 \%$ and $N=41-42 \%$, average grain size of 2-3 $\mu \mathrm{m}$, manufactured by Zakłady Chemiczne "Alwernia" S.A.;

- APP (ammonium polyphosphate) manufactured by Clariant $\mathrm{GmbH}$, commercial name of the product: A;

- MMT and MMT modified with quaternary ammonium salts (oMMT) — manufactured by southern clay products, commercial name of the product: Nanofil 5;

- Expandable graphite-EG 096 manufactured by Synograf S.A., (graphene or oxide graphene);

- Synthetic precipitated silica-experimental product of the Institute of Chemical Fertilizers, Branch 
of the Institute of Inorganic Chemistry in Gliwice.

\subsection{Method of Obtaining Polyester and Epoxy Compositions}

For technical reasons, it was decided to introduce all flame retardants into ready-made polyester or epoxy resins before the addition of hardening agents. Thanks to this procedure, it was possible to modify different types of resins in practice, both at resins "manufacturers" and "processing entities". Additions were stirred in using a low rotation speed mixer. After first stirring with a low speed rotation mixer, the process was continued in an ultrasonic mixer provided with a turbine mixer (approx. 4,500 rev/min). Resultant compositions were additionally ground in a high rotation speed homogenizer, especially if nanocompounds were used in a composition. It was a guarantee of obtaining a stable and homogenous composition of resins with flame retardants after approx. 80-90 min of stirring.

\subsection{Testing Methodology}

\subsubsection{Limiting Oxygen Index}

Following industrial practice, measurements of LOI (limiting oxygen index) were used as a preliminary indication of relative flammability, said index representing mainly the level of flammability of volatile products of polymer decomposition. Measurement of LOI carried out to the standard PN-EN ISO 4589-2:1999/A1:2006.

\subsubsection{Thermogravimetric Analysis}

Thermogravimetric analysis was performed using a thermogravimetric analyser TGA/SDTA 851 device by Metter Toledo. Samples of $10 \pm 2 \mathrm{~g}$ were placed in platinium melting pots with the capacity of $150 \mathrm{~g}$. Heating up progressed in defined cycles, and namely: within the range of $25-800{ }^{\circ} \mathrm{C}$ in air or nitrogen atmosphere and with a heating rate of 10 or $20^{\circ} \mathrm{C} / \mathrm{min}$.

\subsubsection{Cone Calorimeter Tests}

In the presented work, tests were performed using a British cone calorimeter FTT Dual Analysis Cone Calorimeter. Using computer analysis, a number of flammability properties of materials were defined in line according to ISO 5660:2002, part 1 "Reaction to fire tests-head release rate, smoke production and mass loss rate" using an external heat stream of a density of $50 \mathrm{~kW} / \mathrm{m}^{2}$, and air flow rate of $24 \mathrm{l} / \mathrm{s}$. Type of burning reaction initiation-ignition, with a horizontal orientation of samples, is relative to a radiator. A spark fuse was used to ignite gases. Frequency of data compilation is each five seconds. Tests were performed on previously air-conditioned samples, $100 \times 100 \times 10 \mathrm{~mm}^{3}$, having constant relative moisture and constant mass.

\subsubsection{SEM Tests}

SEM tests were performed using a scanning electron microscope BS 301 by Tesla. Tests were performed on specimen sections of sample test blocks and hardened resin composites after their modification.

\section{Results Overview}

Initial assessment of an impact of a compilation of halogen-free flame retardants of flammability level of polyester and epoxy compositions, performed as LOI evaluation, pointed to an especially favorable impact of melamine polyphosphate used in combination with expandable graphite/precipitated silica. A relatively small quantity of a combination of these flame retardants used in a proportion of 15 parts by weight to five parts by weight respectively led to an increase in LOI by $30-43 \%$ for samples of resins without and with reinforcement of glass-reinforced polyester resins fiber compared to non-modified resin only (Table 1). That polyester glass GRP laminates obtained with the discussed composition as a matrix characterized by LOI $>35-45 \%$. MMT modifiers showed a slightly worse flammability reduction impact, which was commented upon in the introductory part of the publication.

Thermogravimetrc analysis of selected polyester compositions was performed in dynamic conditions at a heating rate of $10 \mathrm{~K} / \mathrm{min}$ in air conditions (Fig. 1). Analysis of thermogravimetric curves (TGA) of the process of samples decomposition confirmed a 
Table 1 Determination of limited oxygen index according to PN-EN ISO 4589-2:1999/A1:2006.

\begin{tabular}{lllll}
\hline & & \multicolumn{2}{c}{ Antypirenes } & \multicolumn{2}{c}{$\begin{array}{c}\text { Oxygen index (LOI), \% } \\
\text { PN-EN ISO 4589-2-2006 }\end{array}$} \\
\cline { 2 - 5 } & $\begin{array}{llll}\text { Conventional } \\
\text { FR + Nanofillers }\end{array}$ & $\begin{array}{l}\text { Content } \\
\text { weight, } \%\end{array}$ & $\begin{array}{l}\text { Polyester/epoxy } \\
\text { composites }\end{array}$ & $\begin{array}{l}\text { Polyester/epoxide } \\
\text { GRP laminates }\end{array}$ \\
\hline UP & - & - & 19.5 & 22.9 \\
UP & MPP & 15 & 26.5 & 33.1 \\
UP & MPP + oMMT & $15+5$ & 28.1 & - \\
UP & MPP + EG & $15+5$ & 28.7 & 34.2 \\
UP & MPP + nSiO 2 & $15+5$ & 28.7 & - \\
EP & - & - & 21.1 & 23.8 \\
EP & MPP & 15 & 27.2 & - \\
EP & MPP + oMMT & $15+5$ & 27.7 & 35.1 \\
EP & APP + oMMT & $15+5$ & 27.2 & - \\
\hline
\end{tabular}

Table 2 Thermokinetic properties of selected polyester compositions under heat flux $50 \mathrm{~kW} / \mathrm{m}^{2}$.

\begin{tabular}{|c|c|c|c|c|c|c|}
\hline $\begin{array}{l}\text { Thermokinetic } \\
\text { properties }\end{array}$ & UP & $\mathrm{UP}+\mathrm{MMT}$ & $\mathrm{UP}+\mathrm{MPP}$ & $\begin{array}{l}\mathrm{UP}+\mathrm{MPP} \\
\mathrm{MMT}\end{array}$ & ${ }^{+} \mathrm{UP}+\mathrm{MPP}+\mathrm{EG}$ & $\begin{array}{l}\mathrm{UP}+\mathrm{MPP}+ \\
\mathrm{nSiO}_{2}\end{array}$ \\
\hline $\mathrm{HRR}_{\max }, \mathrm{kW} / \mathrm{m}^{2}$ & 350.28 & 415.34 & 464.87 & 335.51 & 158.6 & 342.32 \\
\hline $\mathrm{HRR}_{\mathrm{av},}, \mathrm{kW} / \mathrm{m}^{2}$ & 212.89 & 245.10 & 279.40 & 218.39 & 108.07 & 236.53 \\
\hline AMLR, $\mathrm{g} / \mathrm{sm}^{2}$ & 13.03 & 14.3 & 17.91 & 11.79 & 4.88 & 15.28 \\
\hline $\mathrm{TSR}, \mathrm{m}^{2} / \mathrm{m}^{2}$ & 5762.7 & $19,002.4$ & $17,316.9$ & $16,291.3$ & $3,251.2$ & $14,581.7$ \\
\hline $\mathrm{THR}, \mathrm{MJ} / \mathrm{m}^{2}$ & 141.6 & 433.8 & 357.7 & 362.5 & 193.9 & 299.2 \\
\hline$t_{\text {do zapłonu }}, s$ & 21 & 26 & 39 & 42 & 29 & 45 \\
\hline$t_{\text {do HRR max }}, s$ & 200 & 95 & 815 & 995 & 45 & 815 \\
\hline $\mathrm{SEA}, \mathrm{m}^{2} / \mathrm{kg}$ & 1024.1 & 936.29 & 955.51 & 960.00 & 366.96 & 954.56 \\
\hline $\begin{array}{l}\mathrm{THR}_{600 \mathrm{~s}} \\
\mathrm{MJ} / \mathrm{m}^{2}\end{array}$ & 138.11 & 169.16 & 164.03 & 108.96 & 45.87 & 145.86 \\
\hline $\begin{array}{l}\text { MARHE, } \\
\mathrm{kW} / \mathrm{m}^{2}\end{array}$ & 382.0 & 300.0 & 323.8 & 235.2 & 106.3 & 273.0 \\
\hline
\end{tabular}

HRR — heat release rate (maximum and average); AMLR — average mass loss rate; TSR — total smoke release; THR — total heat release; $\mathrm{t}_{\mathrm{do} \text { zapłonu }}$ - time to ignition; $\mathrm{t}_{\mathrm{do} \text { HRR max }}$ - time to achieve maximum HRR; SEA-specific extinction area (specific area of smoke obscuration); $\mathrm{THR}_{600 \mathrm{~s}}$ - total heat release heat after $600 \mathrm{~s}$; MARHE—maximum average rate of heat emission.

different cours of thermal decomposition of a nonmodified sample compared to compositions tested analogically and containing multi-ingredient flame retardants. This is proof of the retardand action of this $\mathrm{N} / \mathrm{F}$ with nanofiller system. As one can see, thermal decomposition of modified polyester resins starts at around $280-320{ }^{\circ} \mathrm{C}$ and is earlier than the initial of decomposition of control sample without modifiers. This effect is probable connected with process of decomposition only FR additives. After the ended process of quickly decompositions, it is possible to notice the difference between of analysis of TG curves modified samples with comparison non modified sample at the same temperature of flammability process. Samples which contain a flame retardant, especially MPP and expandable graphite or precipitated nanosilica, undergo basic decomposition at around $420{ }^{\circ} \mathrm{C}$. Introduction to the system of multi-ingredient, especially selected flame retardants led to an increase in the quantity of solid decomposition leftovers.

The CC (cone calorimeter) measuring principle is that of oxygen consumption. This state is that there is a constant relationship between the mass of oxygen consumed from the air and the amount of heat released during the polymer degradation.

The cone calorimeter test was followed up by HRR curves illustrating changes in heat release rate as a function of burning time. Heat release is shown as power per unit of exposed test surface. HRR curves for 
polyester without and with fireproofing in the function of heat flux $50 \mathrm{~kW} / \mathrm{m}^{2}$ are shown in Fig. 2. Analysis of HRR curve shapes for compositions with flame retardants makes it possible to conclude that after the actual maximum increase in HRR, heat release rate decreases in a significantly shorter time compared to an analogically tested sample of a non-modified polyester sample, and there is no second HRR peak. It should be contributed to an isolating effect of flame retardants, thanks to which heat release rate gets stable over time depending on radiation power at constant value.

Those tendency confirmed results for epoxy composites obtained by cone calorimetry analysis (Fig. 3). HHR and ALMR (average mass loss rate) curves for modified epoxy resins-particularly by hybrid antypirenes MPP and $\mathrm{n}-\mathrm{SiO}_{2}$ - decrease in comparison
HRR/MLR for equivalent epoxy without FR modifiers.

These results tend to demonstrate that the improvements in flame retardancy for nanocomposites do not occur by in the process in the gas phase but rather by a change of the combustion act in the condensed phase.

Analysis of SEM micrograph image in Fig. 4 makes it possible to conclude that a multi-ingredient flame retardant was distributed evenly over a polymer matrix, and additions grinding level is sufficient to have a homogenous system without a tendency to agglomerate.

Fig. 4 shows this test. MPP in combination with $\mathrm{Si}_{2}$ or EG was used in order to additionally confirm homogenous morphology of compositions obtained by this way.

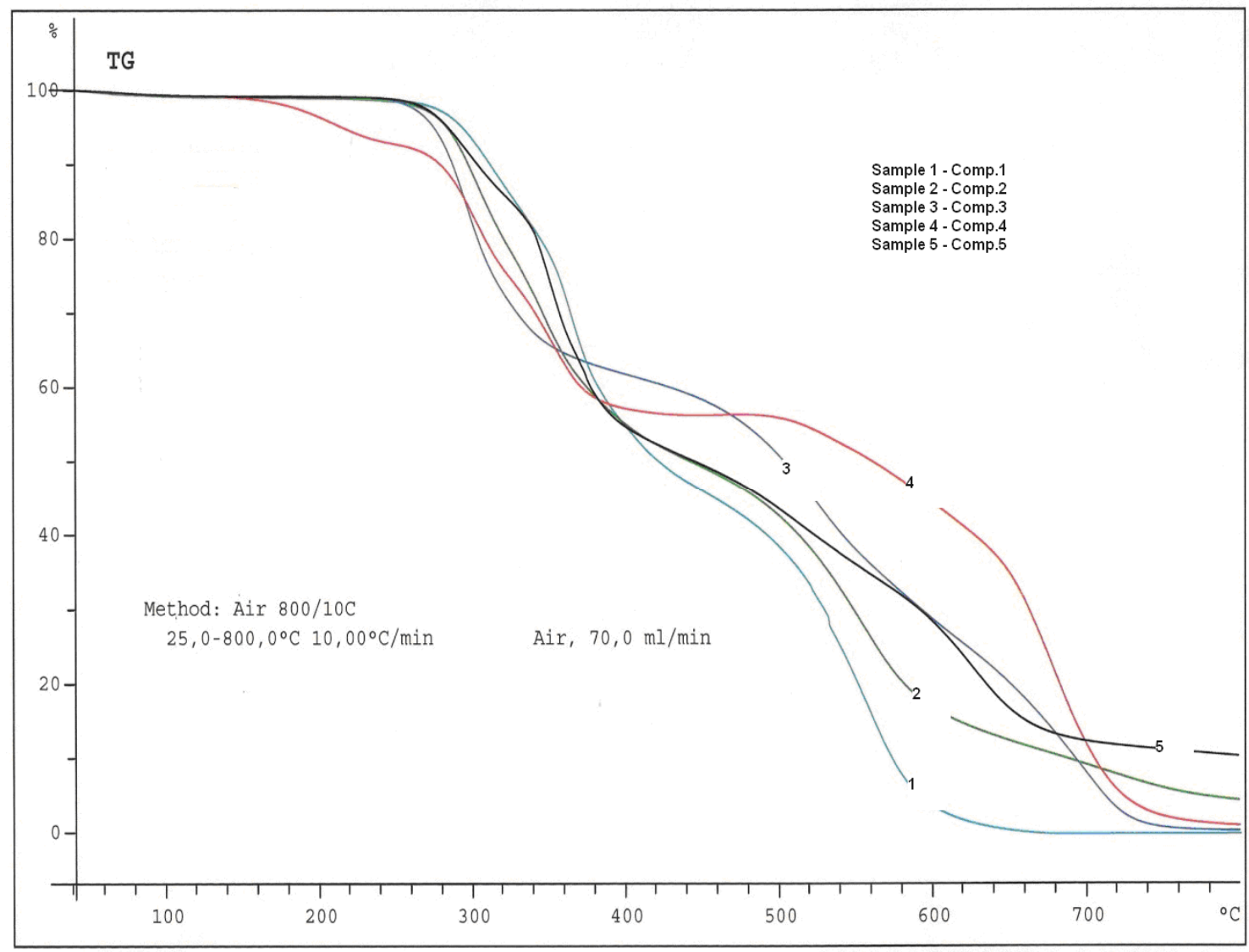

Lab: O/Z EiTG

METTLER TOLEDO STAR System

Fig. 1 Thermogravimetric TGA analysis: (1) UP; (2) UP + 10MPP + 5oMMT; (3) UP + 10MPP + 5n-SiO2; (4) UP + 10PPM + 5EG; (5) UP + 15PPM + 5EG. 

Nanofillers of the Flammability of Thermoset Resins

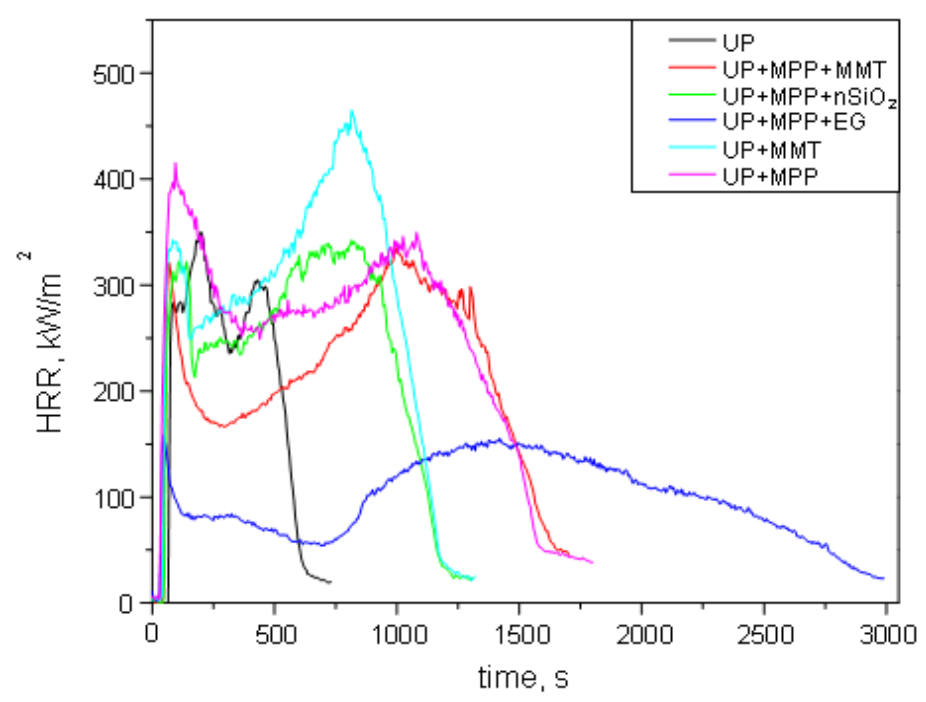

Fig. 2 Course of HRR versus combustion time (unsaturated polyester resins modified flame retardants).

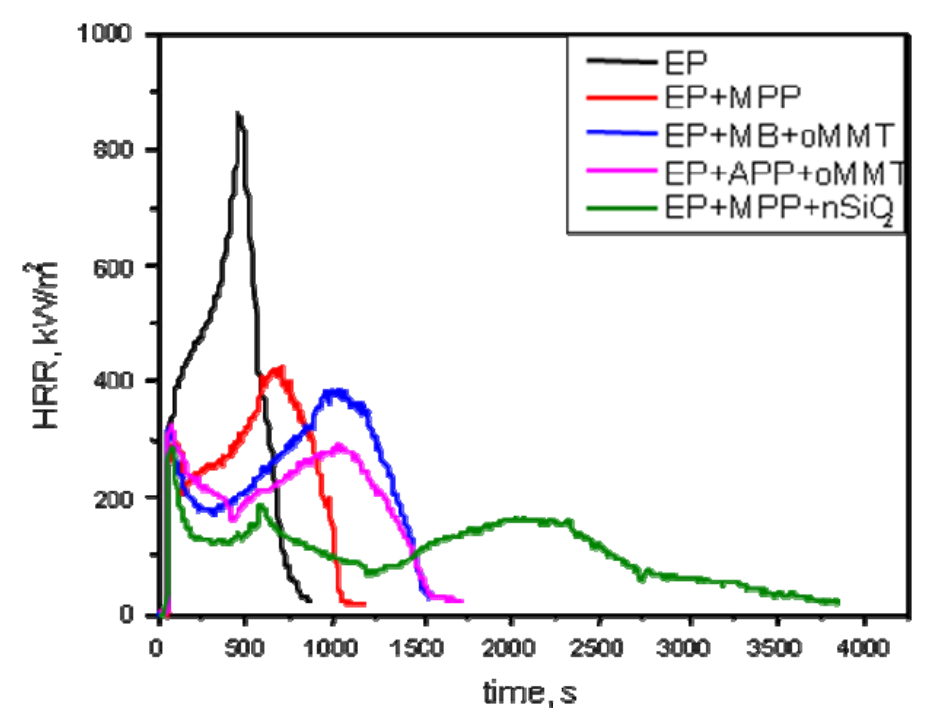

Fig. 3 Course of HRR versus combustion time (epoxy resins modified flame retardants).

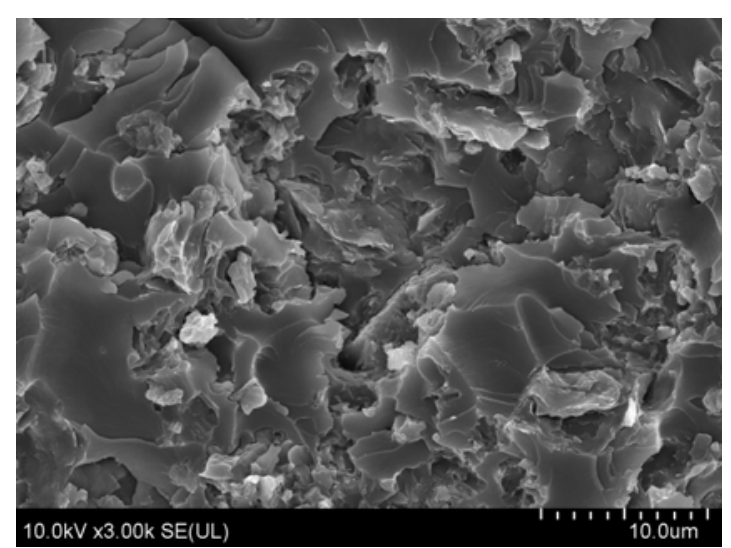

(a)

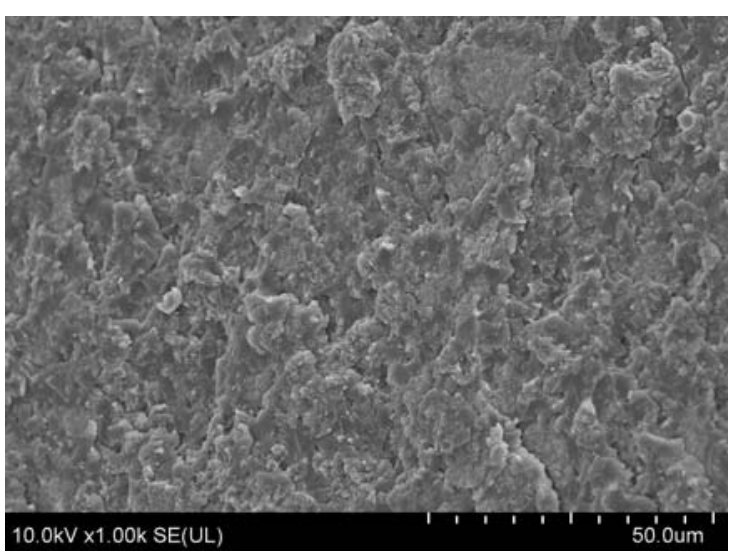

(b)

Fig. 4 SEM micrographs-cross-section of polyester resins modified with multi-component fire retardants: (a) UP + $15 \%$ MPP + 5\%MMT and (b) UP + 15\%MPP + 5\%EG. 
Synergy effect of nanosilica and MMT with conventional flame retardants and their positive impact on thermal resistance and polymer burning profile were confirmed. Our tests suggested that there are at least two processes which reduce flammability level of polymers tested. In the first of them, a nano-filler had a positive impact on coke formation, and in the other one, non-flammable organic material influenced nanosilica/MMT dispersion and in consequence, barrier properties reducing gas diffusion. Synergy effect was also observed while using traditional flame retardants and EG (expandable graphite) or while modifying selected melamine salts and this graphite structure which is active mainly in the solid phase, reducing toxic fumes emissions in an effective way.

\section{Conclusions}

(1) Nanocomposites are a new class of flame retardants thermoset polymer systems. Nanocomposites have many advantages over the traditional flame retardants. Processing of nanocomposites is straight-forward and as the nanocomposites no additional halogen they are considered as an environmentally-friendly alternative.

(2) An effective solution was to use phosphorous-ammonium based modifiers as conventional modifiers in a compilation with nanomodifiers, mainly expandable graphite/graphene and precipitate nanosilica. Multi-ingredient flame and smoke inhibitors showed a positive impact on significant reduction in HRR by approx. $38-70 \%$ (determined by a CC test), increase in LOI by around $30-43 \%$, favorable profile of thermogravimetric curves (TGA) for modified polymers.

(3) Micrograph images of nanocomposites performed by SEM analysis confirmed good distribution of multi-ingredient systems in a polymer matrix without and tendency to agglomerate or sediment. Multi-stage technique of modifiers intercalation with an ultrasonificator turned out to be an effective method of obtaining homogenous nanocomposites with the share of tested.

(4) A multi-ingredient combination of flame retardants turned out to make significant progress in achieving a desired flammability level in thermoset resins. It should be assumed that the presence of conventional flame retardants led to a synergy effect promoting faster formation of a carburized protection layer hindering oxygen flow-through and emission of low-molecule compounds resulting from the process of polymer thermal destruction. That conception is found to be cost effective, industrially viable and many facilitate for development in novel FR thermoset materials.

\section{Acknowledgment}

The study has been carried out with the Key Project PBS 2013-2016 financed by the National Center for Research and Development.

\section{References}

[1] Effective since 2007. "Restriction of Hazardous Substances Directive." (2002/95/EC) and (1907/2006/EC).

[2] Betts, K. S. 2008. "New Thinking on Flame Retardants." Environ Health Prospect 116: A210-3.

[3] Lorenzetti, A., Modest, M., Gallo, E., Shartel, B., Besco, S., and Roso, M. 2012. "Synthesis of Phosphinated Polyurethane Foams with Improved Fire Behaviour." Polymer Degradation and Stability 97 (11): 2364-9.

[4] Saritha, A., Joseph, K., Thomas, S., and Mutaleekrishman, R. 2012. "Chlorobutyl Rubber Nanocomposites as Effective Gas and VOC Barrier Materials." Composites Part A: Applied Science and Manufacturing 43 (6): 864-70.

[5] Kader, M. A., Kim, K., Lee, Y. S., and Nah, C. 2006. "Preparation and Properties of Nitrile Rubber/Montmorillonite Nanocomposites via Latex Blending." Journal of Materials Science 41: 7341-52.

[6] Alongi, J., Brancatelli, B., and Rosace, G. 2012. "Thermal Properties and Combustion Behavior of POSS- and Bohemite-Finished Cotton Fabrics." Journal of Applied Polymer Science 123 (5): 426-36.

[7] Huang, G., Zhuo, A., Wang, L., and Wang, X. 2011. "Preparation and Flammability Properties of Intumescent Flame Retardant-Functionalized Layered Double Hydroxides/Polymethyl Methacrylate Nanocomposites." Materials Chemistry and Physics 130 (1-2): 714-20. 

Nanofillers of the Flammability of Thermoset Resins

[8] Choundhury, A., Bhowmick, A. K., and Ong, Ch. 2010. "Effect of Different Nanoparticles on Thermal, Mechanical and Dynamic Mechanical Properties of Hydrogenated Nitrile Butadiene Rubber Nanocomposites." Journal of Applied Polymer Science 116 (3): 1428-41.

[9] Lao, S. C., Wu, C., Moon, T. J., Koo, J. H., Morgan, A., Pilato, L., and Wissler, G. 2009. "Flame-Retardant Polyamide 11 and 12 Nanocomposites: Thermal and Flammability Properties." Journal of Composite Materials 43 (17): 1803-18.

[10] Mastral, J. F., Berrueco, C., Gea, M., and Ceamanos, J. 2006. "Catalytic Degradation of High Density Polyethylene over Nanocrystalline HZSM-5 Zeolite." Polymer Degradation and Stability 91: 3330-8.

[11] Yarahmadi, N. Y., Jakubowicz, I., and Hjertberg, T. 2010. "Development of Poly (Vinyl Chloride)/Montmorillonite Nanocomposites Using Chelating Agents." Polymer Degradation and Stability 95: 132-7.

[12] Paradise, M., and Goswami, T. 2007. "Carbon Nanotubes-Production and Industrial Applications." Materials a. Design 28 (5): 1477-89.

[13] Kumar, A. P., Depan, D., Tomer, N. S., and Singh, R. P. 2009. "Nanoscale Particles for Polymer Degradation and Stabilization-Trends and Future Perspectives." Progress Polymer Science 34: 479-515.

[14] Samyn, F., Bourbigot, S., Duguesne, S., and Delobel, R. 2007. "Effect of Zinc Borate on the Thermal Degradation of Ammonium Polyphosphate." Termochimica Acta 456 (2): 134-44.

[15] Liu, P., and Zao, M. 2008. "Halloysite Nanotubes/Polystyrene (HNTs/PS) Nanocomposites via in Situ Bulk Polymerization.” Journal of Thermal Analysis and Calorimetry 94 (1): 103-7.

[16] Kandare, E., Kandola, B. K., Price, D., Nazaré, S., and Horrocks, R. A. 2008. "Study of the Thermal Decomposition of Flame-Retarded Unsaturated Polyester Resin by Thermo-Gravimetric Analysis and Py-GC/MS."
Polymer Degradation and Stability 93 (11): 1996-2006.

[17] Katsoulis, C., Kandare, E., and Kandola, B. K. 2011. "The Combined Effect of Epoxy Nanocomposites and Phosphorus Flame Retardant Additives on Thermal and Fire Reaction Properties of Fiber-Reinforced Composites." Journal of Fire and Science 29: 361-83.

[18] Yu, D., Kleemeier, M., Wu, G. M., Schartel, B., Liu, W. O., and Hartwig, A. 2011. "Phosphorus and Silicon Containing Low-Melting Organic-Inorganic Glasses Improve Flame Retardancy of Epoxy/Clay Composites." Macromolecular Materials and Engineering 296 (10): 883-972.

[19] Kicko-Walczak, E., Rymarz, G., and Gajlewicz, I. 2013. "The New Adhesive Polyester with Reduced Flammability for the Production of Modern Piping Systems." Chemical Industry 92 (4): 504-7.

[20] Morgan, A. B., Gagliardi, N. A., Price, W. A., and Galaska, M. L. 2009. "Cone Calorimeter Testing of S2 Glass Reinforced Polymer Composites." Fire and Materials 33: 323-44.

[21] Kicko-Walczak, E., Rajkiewicz, M., and Rymarz, G. "Flame Retardant Epoxy Resins and Epoxy-Glass Reinforced Laminates.” Pol. Pat. Appl. P-393205 (2010) and PCT/PL 2011/000129.

[22] Kicko-Walczak, E., Rymarz, G., Cichy, B., and Stechman, M. "Polyester Composition of Reduced Flammability." Pol. Appl. P-399236 (2012) and PCT/PL2012/000055.

[23] Kicko-Walczak, E., Rymarz, G., and Gajlewicz, I. 2014. "Nanocomposites with Reduced Flammability: Synergy of Conventional Flame Retardants of Nanoparticles in Influencing the Level of Flame Retardancy Resins." Chemical Industry 93 (6): 914-9.

[24] EN ISO 4589-2:1999/A1:2006. Plastics-Determination of Burning Behaviour by Oxygen Index. Part 2: Ambient-Temperature Test.

[25] ISO 5660-1:2002. Reaction-to Fire Tests-Heat Release, Smoke Production and Mass Loss Rate. Part 1: Heat Release Rate (Cone Calorimeter Method). 